\title{
UV Photodissociation Mass Spectrometry Accurately Localize Sites of Backbone Deuteration in Peptides
}

Mistarz, Ulrik Hvid; Bellina, Bruno; Jensen, Pernille Foged; Brown, Jeffery M.; Barran, Perdita E; Rand, Kasper D

Published in:

Analytical Chemistry

DOI:

10.1021/acs.analchem.7b04683

Publication date:

2018

Document version

Publisher's PDF, also known as Version of record

Document license:

CC BY

Citation for published version (APA):

Mistarz, U. H., Bellina, B., Jensen, P. F., Brown, J. M., Barran, P. E., \& Rand, K. D. (2018). UV

Photodissociation Mass Spectrometry Accurately Localize Sites of Backbone Deuteration in Peptides. Analytical Chemistry, 90(2), 1077-1080. https://doi.org/10.1021/acs.analchem.7b04683 


\title{
UV Photodissociation Mass Spectrometry Accurately Localize Sites of Backbone Deuteration in Peptides
}

\author{
Ulrik H. Mistarz, ${ }^{\dagger}$ Bruno Bellina, ${ }^{\ddagger}$ Pernille F. Jensen, ${ }^{\dagger, \|}$ Jeffery M. Brown, ${ }^{\S}$ Perdita E. Barran, ${ }^{*}, \oplus \bullet$
} and Kasper D. Rand ${ }^{*} \dagger \odot$

\author{
${ }^{\dagger}$ Department of Pharmacy, University of Copenhagen, Universitetsparken 2, 2100 Copenhagen, Denmark \\ ${ }^{\ddagger}$ Michael Barber Centre for Collaborative Mass Spectrometry, Manchester Institute of Biotechnology, and Photon Science Institute, \\ The University of Manchester, 131 Princess Street, Manchester, M1 7DN, United Kingdom \\ ${ }^{\S}$ Waters Corporation, Stamford Avenue, Altrincham Road, Wilmslow, SK9 4AX, United Kingdom
}

\section{Supporting Information}

ABSTRACT: Hydrogen/deuterium exchange mass spectrometry (HDX-MS) is now a routinely used technique to inform on protein structure, dynamics, and interactions. Localizing the incorporated deuterium content on a single residue basis increases the spatial resolution of this technique enabling detailed structural analysis. Here, we investigate the use of ultraviolet photodissociation (UVPD) at $213 \mathrm{~nm}$ to measure deuterium levels at single residue resolution in HDX-MS experiments. Using a selectively labeled peptide, we show that UVPD occurs without H/D scrambling as the peptide probe accurately retains its solution-phase deuterium labeling pattern. Our results indicate that UVPD provides an attractive alternative to electron mediated dissociation for increasing the spatial resolution of the HDX-MS experiment, capable of yielding high fragmentation efficiency, high fragment ion diversity, and low precursor ion charge-state dependency.

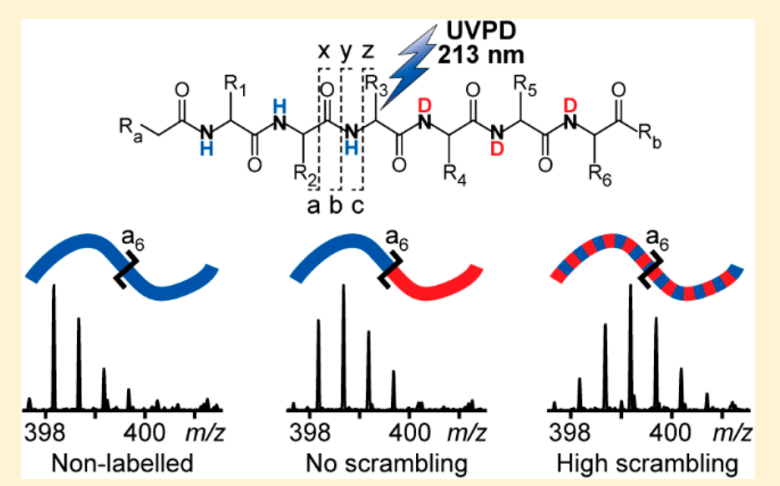

$\mathrm{D}$ etailed insight into the dynamic conformation of proteins is critical for understanding and deciphering the molecular mechanisms of most cellular processes. ${ }^{1}$ Hydrogen/deuterium exchange mass spectrometry (HDX-MS) has become a popular method for studying the conformation, dynamics, and interactions of proteins in solution under a variety of conditions. ${ }^{2-4}$ The method tracks the H/D exchange of protein backbone amides and thus provides a sensitive analytical probe of the hydrogen bonding networks and the solvation of local higher-order structure. An experimental approach to increase the spatial resolution of an HDX-MS experiment is to subject peptides (bottom-up) or intact proteins (top-down) to gas-phase fragmentation (MS/MS) inside the mass spectrometer prior to mass analysis. ${ }^{5}$ This conceptually simple HDX-MS/MS approach, however, requires that the deuterium labeling of backbone amides from solution remains unperturbed during ionization and gas-phase dissociation. $^{6-8}$

The common fragmentation technique of collision induced dissociation (CID) as well as infrared multiphoton dissociation (IRMPD) increase the internal energy of a given ion on a relatively slow timescale $(\mu \mathrm{s}-\mathrm{ms})$ through multiple collisions or absorption of low energy photons, thus mobilizing charging protons prior to covalent bond dissociation., ${ }^{9}$ Both techniques have been shown to randomize the selective deuterium labeling of backbone amides in peptides and proteins, here referred to as $\mathrm{H} / \mathrm{D}$ scrambling. ${ }^{7,8}$ In contrast, fast (picosecond) fragmentation by electron capture dissociation (ECD) was found to proceed without $\mathrm{H} / \mathrm{D}$ scrambling in peptides and proteins. ${ }^{11,12}$ The related technique of electron transfer dissociation (ETD) also proceeds without H/D scrambling ${ }^{13}$ and was in a proof-of-concept study shown to provide a more accessible LC-compatible alternative to ECD, for high-resolution HDX-MS/MS analysis of proteins. ${ }^{14}$ Subsequent applications to other proteins and proteinligand/protein-protein complexes have further underscored the use of ETD to increase the spatial resolution of HDX-MS experiments. $^{15-19}$

Use of a more efficient fragmentation technique could greatly empower the HDX-MS/MS approach. Ultraviolet photodissociation (UVPD) has been shown to provide efficient and highly informative fragmentation of protonated peptides and proteins, producing primarily a/x ions but also $\mathrm{c} /$ $\mathrm{z}$ and $\mathrm{b} / \mathrm{y}$ ions as well as side-chain cleavages ( $\mathrm{v}, \mathrm{w}$, and $\mathrm{d}$ ions). UVPD of peptides and proteins has been implemented at different wavelengths ranging from 157 to $266 \mathrm{~nm}$. At wavelengths above $266 \mathrm{~nm}$, excitation happens primarily for peptides containing aromatic residues. ${ }^{20}$ However, when using higher energy UV photons (lower wavelengths), the primary

Received: November 13, 2017

Accepted: December 21, 2017

Published: December 21, 2017 
accessible chromophore becomes the amide group (with oribital transitions to $\pi^{*}$ either from $\pi$ at $193 \mathrm{~nm}$ or from $n$ at $213 \mathrm{~nm}){ }^{9,21,22}$ The absorption of a single photon at these wavelengths deposits a high amount of energy ( $7.9 \mathrm{eV}$ at 157 $\mathrm{nm}, 6.4 \mathrm{eV}$ at $193 \mathrm{~nm}$, and $5.8 \mathrm{eV}$ at $213 \mathrm{~nm}$ ) which exceeds peptide bond energies of $3-4 \mathrm{eV}^{21}$ resulting in comprehensive fragmentation of both peptides and intact proteins, largely independent of ion charge and size. ${ }^{9}$ Furthermore, UVPD occurs without charge-reduction, thus greatly facilitating detection of both $\mathrm{N}$ - and C-terminal fragments following dissociation and enabling analysis of fragments of singly protonated precursor ions. $^{21}$

The increase in availability and ease of implementation of UV lasers on commercial mass spectrometers, combined with the ability of UV lasers to deliver very short high-energy pulses that deposits high energies into peptide and protein ions on a LC-compatible timescale, makes UVPD a promising method to empower both bottom-up and top-down HDX-MS experiments. It is however critical to first establish if fragment ions from UVPD retain the selective solution-phase deuterium labeling of backbone amides in a polypeptide.

Here, we investigate the occurrence of $\mathrm{H} / \mathrm{D}$ scrambling at backbone amide positions during UVPD of a regioselective deuterium labeled 12-mer peptide, peptide P1 (HHHHHHII$\mathrm{KIIK}){ }^{23}$ For this peptide, differences in the intrinsic H/D exchange rates of the constituent amino acids allow deuterium to be retained solely in the backbone amide residues in the $\mathrm{C}$ terminal part (-IIKIIK) for several minutes in solution. ${ }^{23}$ Upon ionization, gas-phase fragmentation, and mass analysis, the deuterium content can be measured for both intact precursor ion and MS/MS fragment ions, which enables a sensitive quantitation of the level of $\mathrm{H} / \mathrm{D}$ scrambling.

UVPD was performed on peptide P1 using a $213 \mathrm{~nm}$ laser operated at $1 \mathrm{kHz}$ and delivering $2.5 \mu \mathrm{J} /$ pulse, which was implemented on a commercially available ion mobility enabled high-resolution Q-TOF mass spectrometer (Figure 1a). The triply protonated peptide P1 was mass selected in the quadrupole, trapped in the trap $\mathrm{T}$-Wave ion guide and photoactivated for $600 \mathrm{~ms}$. The photofragments are then extracted to the TOF for mass analysis (Figure S-1). UVPD of the triply protonated peptide ion resulted in multiple singly or doubly charged fragment ions, primarily $a / x$ and $c / z$ ions of high abundance, $b / y$ ions of low abundance, a single $d$ ion, and a His immonium ion $/ \mathrm{a}_{1}$ ion (Figure $1 \mathrm{~b}-\mathrm{d}$ ).

The relative abundance of the different fragment ions is plotted in Figure S-2. The deuterium content of all fragment ions of sufficient signal-to-noise ratio $(\mathrm{S} / \mathrm{N}>15)$ was used for quantitating $\mathrm{H} / \mathrm{D}$ scrambling (Figure $1 \mathrm{~d}$ in bold). Further details concerning experimental settings and data analysis are provided in the Supporting Information. UVPD of the quadruply protonated peptide ion, recorded using the same settings, did not yield fragment ions of sufficient intensity and was not optimized.

To avoid collisional activation and thus $\mathrm{H} / \mathrm{D}$ scrambling in the front-end of the mass spectrometer prior to UVPD of the labeled peptide, a systematic optimization of ion source parameters was performed to facilitate gentle ionization and ion transport. ETD has been shown to proceed inherently without $\mathrm{H} / \mathrm{D}$ scrambling. ${ }^{13,24}$ By performing ETD in the trap T-Wave of the Q-TOF instrument, we quantitated the influence of several instrument parameters on $\mathrm{H} / \mathrm{D}$ scrambling for the triply protonated peptide P1 prior to fragmentation (Figure S-3). Four parameters had a significant impact on H/D

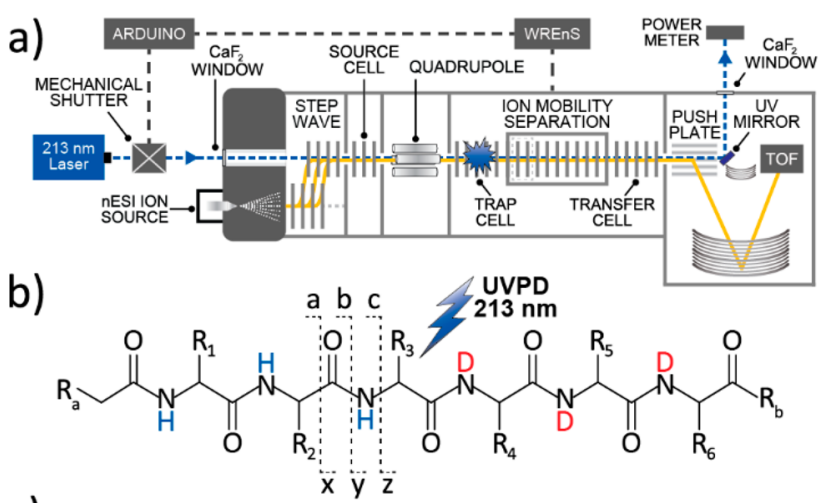

c)
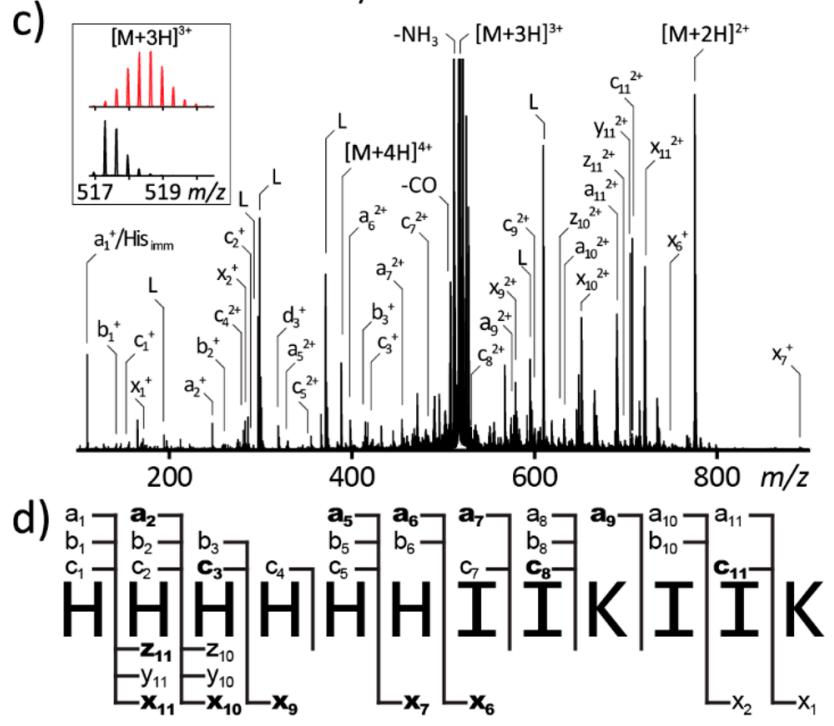

Figure 1. UVPD of the regioselective deuterium labeled peptide P1. (a) Schematic of the UVPD enabled mass spectrometer. The blue and yellow lines, respectively, show the laser beam and the ion beam. (b) Schematic of the different backbone fragment ion types produced during UVPD. (c) Mass spectrum of the triply protonated peptide P1 following UVPD (70× zoom on $y$-axis), with annotation of identified fragment ions. L indicates laser generated artifact peaks (see Supporting Information). The triply protonated precursor ion when unlabeled (black) and labeled (red) is shown in the inset. (d) Amino acid sequence of peptide P1 and UVPD fragments identified for peptide P1. Fragment ions of suitable $\mathrm{S} / \mathrm{N}$ used for $\mathrm{H} / \mathrm{D}$ scrambling calculations are in bold.

scrambling (Table S-1). At elevated settings, the "sampling cone" induced complete randomization of the deuterium label of peptide P1, in good correlation to earlier work. ${ }^{25}$ The other three important parameters "cone gas", "source offset", and "StepWave 2 offset", the latter two unique to the StepWave ion guide of this Q-TOF instrument, induced a moderate increase in scrambling of $15-25 \%$ at elevated settings (Figure S-3). The four parameters were tuned to define "mild" ion source settings that allowed maximum ion transmission while retaining minimal scrambling $(<10 \%)$ in ETD-generated $\mathrm{c} / \mathrm{z}$ ions. "Harsh" ion source settings were similarly defined that induced scrambling in ETD-generated $\mathrm{c} / \mathrm{z}$ ions (Table S-1). The harsh conditions were obtained from the mild conditions by increasing the electrostatic potential of the sampling cone from 20 to $105 \mathrm{~V}$. UVPD was performed for labeled peptide P1 under both mild and harsh conditions (Figure 2).

The deuterium content of $a, x$, and $c$ ions, as well as a single $\mathrm{z}$ ion resulting from UVPD at mild conditions was plotted as a function of fragment ion length and compared to theoretical 


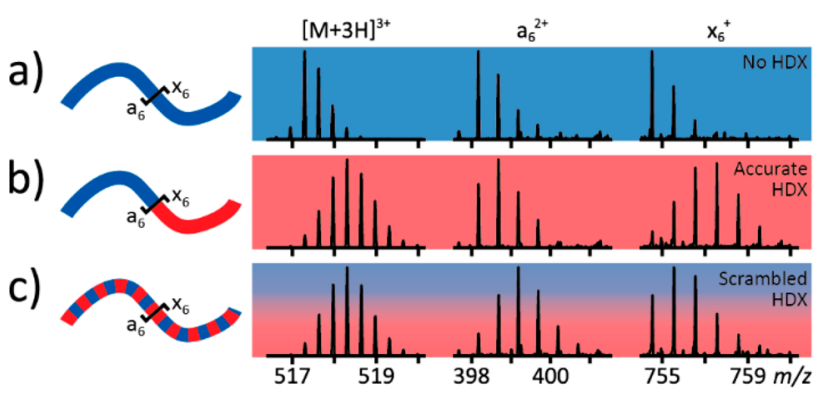

d)

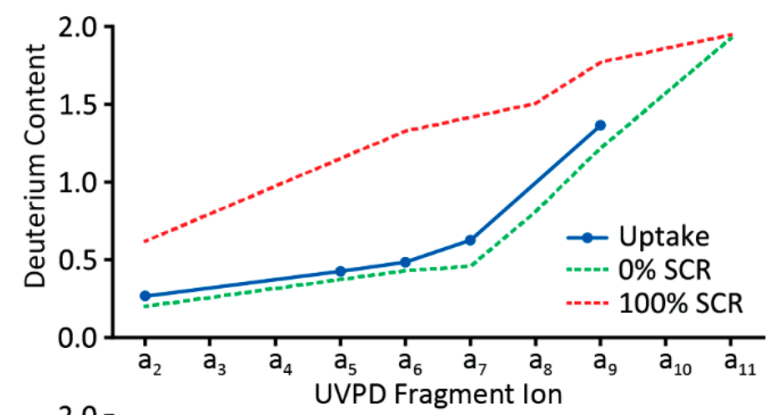

e)

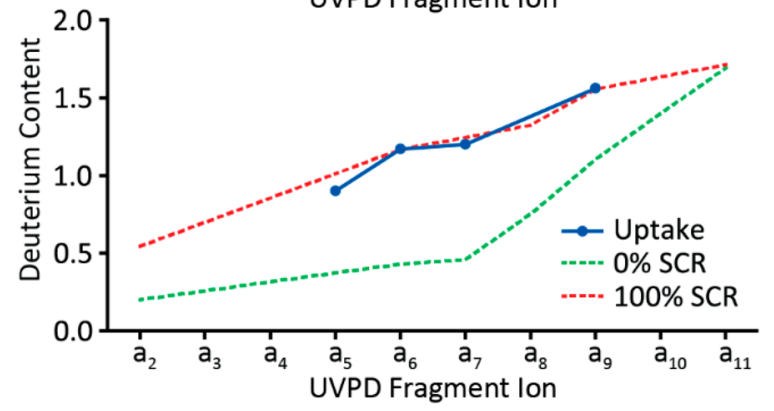

Figure 2. Quantitating H/D scrambling during UVPD using peptide P1. Illustration of the regioselective deuterium labeling and corresponding mass spectra of triply protonated precursor, $\mathrm{a}_{6}{ }^{2+}$, and $\mathrm{x}_{6}{ }^{+}$fragment ions (left to right), from an unlabeled sample (a) and labeled samples analyzed at "mild" (b) or "harsh" (c) ion source settings for minimal or induced HDX scrambling, respectively. Plots of deuterium content measured as a function of fragment ion length used for assessing H/D scrambling by UVPD, with mass spectrometry parameters tuned for mild (d) or harsh (e) ionization. Fragment ion $\mathrm{a}_{2}$ was not present at suitable $\mathrm{S} / \mathrm{N}$ during UVPD at harsh ionization conditions. Calculated deuterium contents for a-type fragment ions are shown in blue. Green and red dotted lines indicate theoretical $0 \%$ and $100 \%$ scrambling (SCR), respectively.

models in the case of either $0 \%$ or $100 \%$ scrambling (Figure 2). Results from one a-type ion series are shown in Figure 2d, with data from replicate measurements and other fragment ion types shown in Figure S-4. Evidently, a, c, x, and $\mathrm{z}$ fragment ions from UVPD at mild ion source conditions reproducibly retained the regioselective labeling pattern of the intact peptide from solution. The deuterium contents of all detected fragment ions correlated closely with the theoretical model for $0 \%$ scrambling ( $<10 \%$ scrambling). The fact that both $\mathrm{a} / \mathrm{x}$ and $\mathrm{c} / \mathrm{z}$ ions were generated by UVPD at $213 \mathrm{~nm}$ without H/D scrambling suggests that the $a / x$ and $c / z$ fragments were generated on a comparably fast timescale through mechanisms that do not involve reversible protonation or hydrogen migration of backbone amide groups. In contrast, the deuterium content of $a / x$ and $c / z$ fragment ions generated through UVPD of labeled peptide P1 at harsh ion source conditions (Figures $2 \mathrm{e}$ and $\mathrm{S}-5 \mathrm{a}$ ), correlated closely with the model for $100 \%$ scrambling (>85\% scrambling). This control experiment validated the applied analytical approach by demonstrating the ability of UVPD-generated fragment ions of the selectively labeled peptide to report the occurrence of $\mathrm{H} / \mathrm{D}$ scrambling.

We next compared the occurrence of $\mathrm{H} / \mathrm{D}$ scrambling in labeled peptide P1 following UVPD, ETD, or CID performed under identical mild ion source conditions (Figures 3 and S-5).

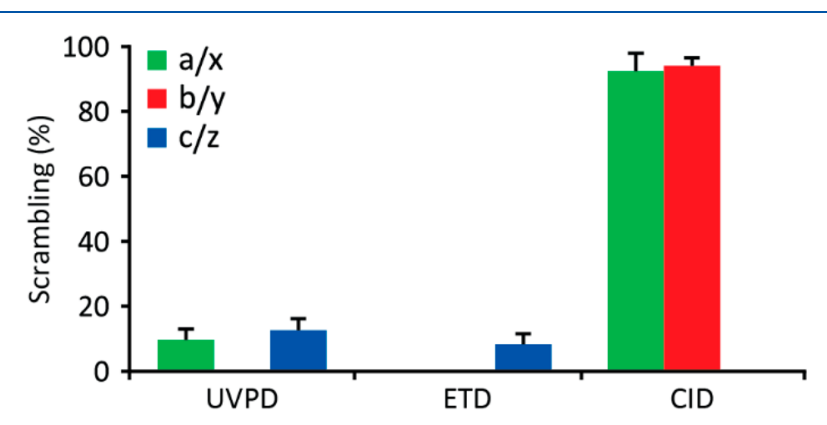

Figure 3. Comparison of $\mathrm{H} / \mathrm{D}$ scrambling in the regioselective deuterium labeled peptide P1 following UVPD, ETD, or CID at mild ion source conditions. The degree of $\mathrm{H} / \mathrm{D}$ scrambling was quantitated for all fragment ion types present at suitable ion abundance. Experiments were done in at least three replicates, and the error bars indicate single standard deviations.

ETD yielded $\mathrm{c} / \mathrm{z}$ fragment ions with a similar low degree of $\mathrm{H} /$ $\mathrm{D}$ scrambling $(8 \% \pm 3 \%)$ to $\mathrm{a} / \mathrm{x}$ and $\mathrm{c} / \mathrm{z}$ fragment ions from UVPD. We assign the minimal residual scrambling level detected $(<10 \%)$ to method uncertainty ${ }^{6}$ and minor inherent $\mathrm{H} / \mathrm{D}$ scrambling occurring during ion transmission in the mass spectrometer at mild ion source conditions. Comparative UVPD and ETD experiments performed at harsh ion source conditions both produced full scrambling at $>90 \%$ (Figure S5 ). Furthermore, CID-generated $a / x$ and $b / y$ fragment ions of labeled peptide P1 displayed a complete randomization of the solution-phase labeling pattern ( $>90 \%$ scrambling), as previously shown for $b / y$ ions. ${ }^{7}$ Notably, UVPD gave $a / x$ fragment ions with negligible $\mathrm{H} / \mathrm{D}$ scrambling, demonstrating differences in the mechanism by which $\mathrm{a}$ and $\mathrm{x}$ ions are generated in UVPD and CID.

In conclusion, by measuring the deuterium content of $a / x$ and $c / z$ fragment ions of the selectively model peptide, our results show that UVPD at $213 \mathrm{~nm}$ can proceed without H/D scrambling. By demonstrating the ability of UVPD to accurately measure the deuterium levels of individual amide hydrogens in a peptide, our results show the feasibility of using UVPD to increase the spatial resolution of an HDX-MS experiment. Distinct mechanisms may give rise to the diverse fragment ions observed during UVPD at $213 \mathrm{~nm}$ (e.g., a/x, c/z, $\mathrm{b} / \mathrm{y}$ ). Here, we observed that both singly and doubly protonated $\mathrm{a} / \mathrm{x}$ and $\mathrm{c} / \mathrm{z}$ ions were generated without randomization of the deuterium labeling of backbone amide groups, supporting that such fragment ions are generated by direct mechanisms occurring promptly after absorption of the high-energy photon $(5.8 \mathrm{eV})$ on a microsecond to nanosecond timescale. ${ }^{20}$ UVPD-generated $\mathrm{a} / \mathrm{x}$ and $\mathrm{c} / \mathrm{z}$ ions are thus formed faster than the rate of proton mobilization in the activated peptide and the underlying radical-based mechanism(s) do not require migration of hydrogens to facilitate bond cleavage. Absorption of photons of even higher energy during UVPD at 193 or $157 \mathrm{~nm}(6.4-7.9 \mathrm{eV})$ is therefore likely also to yield $\mathrm{a} / \mathrm{x}$ and $\mathrm{c} / \mathrm{z}$ ions without $\mathrm{H} / \mathrm{D}$ scrambling, although this remains to be validated experimentally. While the low abundance $b / y$ ions 
formed during $213 \mathrm{~nm}$ UVPD of peptide P1 precluded reliable quantitative analysis, our results are in line with mechanistic studies of UVPD at $157 \mathrm{~nm}$ suggesting that all fragment ions from UVPD using short-wavelength lasers originate from fast radical-based mechanisms. ${ }^{26}$ Our findings indicate that UVPD at $213 \mathrm{~nm}$ offers a powerful complement to ETD in bottom-up HDX-MS/MS workflows, with the potential to provide alternative fragmentation, with less dependency on size and charge state of the precursor ion, ${ }^{27}$ and even allow the extraction of site-specific information for singly charged peptides. ${ }^{22}$ In this study, UVPD was performed under settings providing optimal fragment ion yields during a direct infusion experiment thus enabling quantitation of $\mathrm{H} / \mathrm{D}$ scrambling at maximum sensitivity. No attempts were made to optimize data acquisition parameters or duty cycle (including photoactivation time and trapping time) toward sample introduction by LC. Furthermore, the setup is compatible with other 213 $\mathrm{nm}$ lasers capable of more efficient UVPD by delivering higher energies per pulse. Finally, the current implementation of UVPD on a high resolution Q-TOF capable of ion mobility separation $^{28,29}$ could enhance extraction of residue-specific deuterium levels from overlapping fragment ions from UVPD of larger peptides and intact proteins in both bottom-up and top-down HDX-MS/MS applications.

\section{ASSOCIATED CONTENT}

\section{S Supporting Information}

The Supporting Information is available free of charge on the ACS Publications website at DOI: 10.1021/acs.analchem.7b04683.

Additional description of materials and methods used in this work; implementation of $213 \mathrm{~nm}$ UVPDS; abundance of fragment ion types observed during UVPD of peptide P1; effects on various ion source settings on $\mathrm{H} / \mathrm{D}$ scrambling; quantitating $\mathrm{H} / \mathrm{D}$ scrambling in UVPD, ETD, and CID fragment ions; important ion source settings for minimizing $\mathrm{H} / \mathrm{D}$ scrambling in the Synapt G2-Si Q-TOF instrument (PDF)

\section{AUTHOR INFORMATION}

\section{Corresponding Authors}

*E-mail: perdita.barran@manchester.ac.uk.

*E-mail: kasper.rand@sund.ku.dk.

\section{ORCID $\odot$}

Perdita E. Barran: 0000-0002-7720-586X

Kasper D. Rand: 0000-0002-6337-5489

\section{Present Address}

"P.F.J.: Symphogen A/S, Pederstrupvej 93, DK-2750 Ballerup, Denmark.

\section{Author Contributions}

All authors have given approval to the final version of the manuscript.

\section{Notes}

The authors declare no competing financial interest.

\section{ACKNOWLEDGMENTS}

The authors gratefully acknowledge the financial support from the Danish Council for Independent Research (Sapere Aude Grant-DFF-4184-00537A), the British Biotechnology and Biological Sciences Research Council (BBSRC grants BB/ L002655/1 and BB/L016486/1), and Waters Corporation.
U.H.M. gratefully acknowledges the Elite Research (EliteForsk) travel grant from the Ministry of Higher Education and Science.

\section{REFERENCES}

(1) Teilum, K.; Olsen, J. G.; Kragelund, B. B. Cell. Mol. Life Sci. 2009, 66 (14), 2231-2247.

(2) Zhang, Z.; Smith, D. L. Protein Sci. 1993, 2 (4), 522-531.

(3) Engen, J. R. Anal. Chem. 2009, 81 (19), 7870-7875.

(4) Marciano, D. P.; Dharmarajan, V.; Griffin, P. R. Curr. Opin. Struct. Biol. 2014, 28 (1), 105-111.

(5) Rand, K. D.; Zehl, M.; Jørgensen, T. J. D. Acc. Chem. Res. 2014, 47 (10), 3018-3027.

(6) Rand, K. D. Int. J. Mass Spectrom. 2013, 338, 2-10.

(7) Jørgensen, T. J. D.; Gårdsvoll, H.; Ploug, M.; Roepstorff, P. J. Am. Chem. Soc. 2005, 127 (8), 2785-2793.

(8) Demmers, J. A. A.; Rijkers, D. T. S.; Haverkamp, J.; Killian, J. A.; Heck, A. J. R. J. Am. Chem. Soc. 2002, 124 (37), 11191-11198.

(9) Brodbelt, J. S. Chem. Soc. Rev. 2014, 43, 2757-2783.

(10) Wysocki, V. H.; Tsaprailis, G.; Smith, L. L.; Breci, L. A. J. Mass Spectrom. 2000, 35 (12), 1399-1406.

(11) Rand, K. D.; Adams, C. M.; Zubarev, R. A.; Jørgensen, T. J. D. J. Am. Chem. Soc. 2008, 130 (4), 1341-1349.

(12) Pan, J.; Han, J.; Borchers, C. H.; Konermann, L. J. Am. Chem. Soc. 2009, 131 (35), 12801-12808.

(13) Zehl, M.; Rand, K. D.; Jensen, O. N.; Jørgensen, T. J. D. J. Am. Chem. Soc. 2008, 130 (51), 17453-17459.

(14) Rand, K. D.; Zehl, M.; Jensen, O. N.; Jørgensen, T. J. D. Anal. Chem. 2009, 81 (14), 5577-5584.

(15) Landgraf, R. R.; Chalmers, M. J.; Griffin, P. R. J. Am. Soc. Mass Spectrom. 2012, 23 (2), 301-309.

(16) Huang, R. Y.-C.; Garai, K.; Frieden, C.; Gross, M. L. Biochemistry 2011, 50 (43), 9273-9282.

(17) Masson, G. R.; Maslen, S. L.; Williams, R. L. Biochem. J. 2017, 474 (11), 1867-1877.

(18) Jensen, P. F.; Larraillet, V.; Schlothauer, T.; Kettenberger, H.; Hilger, M.; Rand, K. D. Mol. Cell. Proteomics 2015, 14 (1), 148-161.

(19) Mistarz, U. H.; Brown, J. M.; Haselmann, K. F.; Rand, K. D. Anal. Chem. 2014, 86 (23), 11868-11876.

(20) Ly, T.; Julian, R. R. Angew. Chem., Int. Ed. 2009, 48 (39), $7130-7137$.

(21) Reilly, J. P. Mass Spectrom. Rev. 2009, 28, 425-447.

(22) Girod, M.; Sanader, Z.; Vojkovic, M.; Antoine, R.; MacAleese, L.; Lemoine, J.; Bonacic-Koutecky, V.; Dugourd, P. J. Am. Soc. Mass Spectrom. 2015, 26 (3), 432-443.

(23) Rand, K. D.; Jørgensen, T. J. D. Anal. Chem. 2007, 79 (22), $8686-8693$

(24) Abzalimov, R. R.; Kaplan, D. A.; Easterling, M. L.; Kaltashov, I. A. J. Am. Soc. Mass Spectrom. 2009, 20 (8), 1514-1517.

(25) Rand, K. D.; Pringle, S. D.; Morris, M.; Engen, J. R.; Brown, J. M. J. Am. Soc. Mass Spectrom. 2011, 22 (10), 1784-1793.

(26) Cui, W.; Thompson, M. S.; Reilly, J. P. J. Am. Soc. Mass Spectrom. 2005, 16 (8), 1384-1398.

(27) Shaw, J. B.; Li, W.; Holden, D. D.; Zhang, Y.; Griep-Raming, J.; Fellers, R. T.; Early, B. P.; Thomas, P. M.; Kelleher, N. L.; Brodbelt, J. S. J. Am. Chem. Soc. 2013, 135 (34), 12646-12651.

(28) Theisen, A.; Yan, B.; Brown, J. M.; Morris, M.; Bellina, B.; Barran, P. E. Anal. Chem. 2016, 88 (20), 9964-9971.

(29) Bellina, B.; Brown, J. M.; Ujma, J.; Murray, P.; Giles, K.; Morris, M.; Compagnon, I.; Barran, P. E. Analyst 2014, 139 (24), 6348-6351. 